\title{
A Novel Antifungal System With Potential for Prolonged Delivery of Histatin 5 to Limit Growth of Candida albicans
}

\author{
Carolina R. Zambom ${ }^{1 *}$, Fauller H. da Fonseca ${ }^{1}$, Edson Crusca Jr. ${ }^{1}$, Patrícia B. da Silva ${ }^{2}$, \\ Fernando R. Pavan ${ }^{3}$, Marlus Chorilli ${ }^{2}$ and Saulo S. Garrido ${ }^{1 *}$
}

'Department of Biochemistry and Chemical Technology, Institute of Chemistry, UNESP - São Paulo State University, Araraquara, Brazil, '2Department of Drugs and Medicines, School of Pharmaceutical Sciences of Araraquara, UNESP - São Paulo State University, Araraquara, Brazil, ${ }^{3}$ Department of Biological Sciences, School of Pharmaceutical Sciences of Araraquara, UNESP - São Paulo State University, Araraquara, Brazil

OPEN ACCESS

Edited by:

Renata Katsuko Takayama Kobayashi, State University of Londrina, Brazil

Reviewed by:

Terezinha Inez Svidzinski, State University of Maringá, Brazil

Sumant Puri,

Temple University, United States

*Correspondence: Carolina R. Zambom carolinarz@gmail.com

Saulo S. Garrido saulo.santesso@unesp.br

Specialty section:

This article was submitted to Antimicrobials, Resistance and

Chemotherapy,

a section of the journal

Frontiers in Microbiology

Received: 13 December 2018

Accepted: 04 July 2019

Published: 30 July 2019

Citation:

Zambom CR, da Fonseca FH, Crusca E Jr, da Silva PB, Pavan FR, Chorilli M and Garrido SS (2019) A Novel Antifungal System With Potential for Prolonged Delivery of Histatin 5 to Limit Growth of Candida albicans.

Front. Microbiol. 10:1667. doi: 10.3389/fmicb.2019.01667
Currently $75-88 \%$ of fungal infections are caused by Candida species, and Candida albicans is the main microorganism that causes these infections, especially oral candidiasis. An option for treatment involves the use of the antifungal peptide Histatin 5 (Hst 5), which is naturally found in human saliva but undergoes rapid degradation when present in the oral cavity, its site of action. For this reason, it is important to develop a way of applying this peptide to the oral lesions, which promotes the gradual release of the peptide. In the present study, we have evaluated the development of liposomes of different lipid compositions, loaded with the peptide as a way to promote its release slowly and gradually, preserving its antifungal potential. For this, the peptide OWHistatin 5, an analog of the peptide Hst 5, was synthesized, which contains the amino acid tryptophan in its sequence. The solid phase synthesis method was used, followed by cleavage and purification. The liposomes were produced by thin film hydration technique in three different lipid compositions, F1, F2, and F3 and were submitted to an extrusion and sonication process to standardize the size and study the best technique for their production. The liposomes were characterized by dynamic light scattering, and tests were performed to determine the encapsulation efficiency, release kinetics, stability, and evaluation of antifungal activity. The extruded liposomes presented average size in the range of $100 \mathrm{~nm}$, while sonicated liposomes presented a smaller size in the range of $80 \mathrm{~nm}$. The encapsulation efficiency was higher for the sonicated liposomes, being 34.5\% for F1. The sonicated F3 presented better stability when stored for 60 days at $4^{\circ} \mathrm{C}$. The liposomes showed the ability to release the peptide for the total time of $96 \mathrm{~h}$, with the first peak after $5 \mathrm{~h}$, and a further increase of the released after $30 \mathrm{~h}$. Time-kill assay showed that the liposomes were able to control yeast growth for $72 \mathrm{~h}$. The data suggest that the liposomes loaded with OWHistatin 5 maintained the action of the peptide and were able to limit the growth of $C$. albicans, being a suitable system for use in the treatment of oral candidiasis.

Keywords: antifungal system, oral candidiasis, Candida albicans, Histatin 5, liposomes 


\section{INTRODUCTION}

In recent decades, there has been an increase in mortality caused by fungal infections which have gone from isolated and rare cases to one of the greatest global public health problems especially among immunocompromised individuals (Robbins et al., 2016). This fact is related to medical interventions such as chemotherapy for cancer treatment, immunosuppression for transplantation, and the high prevalence of HIV infections (Berkow and Lockhart, 2017). This has allowed the appearance of prevalent fungal infections among which the main pathogens are Candida albicans, Cryptococcus neoformans, and Aspergillus fumigatus (Robbins et al., 2016). These pathogens cause the death of more than 1 million people annually in the world with $75-88 \%$ of fungal infections being caused by Candida species, which generated a cost of $\$ 1.7$ billion for public health in the US and the increase of severe cases of hospital infections (Berkow and Lockhart, 2017).

C. albicans exists as a commensal microorganism of the skin, mouth, and gastrointestinal tract. Its spread is controlled by coexistence with the normal human microbiota and also by the processes of defense related to immune system. However, when there is suppression of the immune response against C. albicans, colonization of the tissue occurs establishing the infection, more commonly manifested as candidiasis and oropharyngeal candidiasis (Robbins et al., 2016).

Because it is a polymorphic microorganism, C. albicans is able to transition between the yeast and hypha lifestyles. The hypha has greater resistance and greater invasive capacity in tissues compared to the yeast. For this reason, this species demonstrates resistance to the most common antifungals, such as polyenes (nystatin and amphotericin B) or azoles (itraconazole, miconazole, and fluconazole) (Hawser and Douglas, 1995).

An alternative treatment is the use of fluconazole and amphotericin B, which are more effective but have higher levels of toxicity and should not be used in constant or routine doses (Johnson et al., 1995; Cannon et al., 2007). For this reason, the search for new treatment options and new drugs are constantly developing mainly in the biotechnology field. An example of this is the biologically active peptides naturally found in living organisms such as the antimicrobial peptides (AMPs) of Histatin class.

One of these AMPs, that is, the focus of this data is Histatin 5 (Hst 5), one of the peptides of the Histatin class naturally present in human saliva and potentially active against pathogenic yeast such as C. albicans (Helmerhorst et al., 1999; Baev et al., 2002). Hst 5 is a peptide of about $3 \mathrm{kDa}$ composed of a linear sequence of 24 amino acid residues, has a positive charge at physiological $\mathrm{pH}$, assumes a-helix structure in DMSO (dimethylsulfoxide) and TFE (trifluorethanol)/water, and in water preferably takes on a random structure (Seo et al., 2012).

Recent studies have demonstrated that Hst 5 is able to inhibit C. albicans growth in concentrations ranging from 25 to $800 \mu \mathrm{g} \mathrm{ml}^{-1}$ (Moffa et al., 2015b) with MIC of $25 \mu \mathrm{g} \mathrm{ml}^{-1}$ (Konopka et al., 2010). Another feature of this peptide is its ability to protect the oral epithelium from C. albicans infection, proven in in vitro studies with gingival fibroblast cells, in which at a concentration of $50 \mu \mathrm{g} \mathrm{ml} \mathrm{m}^{-1}$, there was no invasion of the cells by the microorganism (Moffa et al., 2015b).

However, we have reported that Hst 5 undergoes rapid degradation, and the proteolysis has been the major focus aimed at explaining that degradation causes the reduction or even loss of its antifungal activity (Moffa et al., 2015a). Another problem observed was that Hst 5 can interact with other proteins present in saliva, such as amylase, resulting in a complex free of antifungal activity (Moffa et al., 2015a).

One way to overcome this problem would be the use of nanocarriers, such as liposomes, that can incorporate the peptide and increase its availability at the site of action. Liposomes have been used in therapeutics for more than 40 years, presenting many advantages, including biocompatibility, because they are constituted by phospholipids, such as the biological membranes of the cells (Chorilli et al., 2013).

The liposome advantage is related to a longer duration of the therapeutic effect of the drug (De Araújo et al., 2003), prolonging its action and allowing larger doses to be administered without the risks of toxicity (Frézard et al., 2005). Thus, there are a lower number of drug administrations throughout the treatment, as demonstrated by studies with liposome-encapsulated LL-37 peptide which showed improved bioactivity and reduced toxicity for treatment of HSV-1. The studies carried out indicated the LL-37 liposomal formulation as an effective system for carrying and delivering the peptide to the action target (Ron-Doitch et al., 2016).

Liposomes are also effective in promoting protection against external degradation by enzymes or by proteolytic degradation (Voltan et al., 2016). For this reason, they are used for encapsulation of peptides and proteins. Liposomes encapsulated with peptide ghrelin, used to treat cachexia, characterized as extreme weakness in patients afflicted with chronic diseases, showed that liposomes were able to protect the peptide from the attack of trypsin and carboxylesterase enzymes by 20 and $81 \%$, respectively (Salade et al., 2017).

Thus, these positive aspects about the use of liposomes motivated us to elaborate a system to apply Histatin 5, with the main interest in increasing peptide availability at the site of action, causing its fungicidal effect to be preserved and intensified over a longer period, thus optimizing treatment against C. albicans.

\section{MATERIALS AND METHODS}

\section{Chemicals and Microorganisms}

Reagents $\mathrm{N}$ - $\alpha$-fluorenylmethyloxycarbonyl-amino acids (Fmocamino acid) and Fmoc-tyr-wang resin were purchased from Novabiochem $^{\circledR}$. N-hydroxybenzotriazole (HOBt), N, N'diisopropylcarbodiimide (DIC), dichloromethane (DCM), dimethylformamide (DMF), and trifluoroacetic acid (TFA) were purchased from Fluka ${ }^{\circledR}$. Ethanedithiol (EDT), glacial acetic acid, dimethylformamide (DMF), dimethyl sulfoxide (DMSO), chloroform, and grade HPLC acetonitrile (ACN) were purchased from Merck ${ }^{\circledR}$. The microorganism C. albicans (ATCC 90028) was donated by the National Institute of Quality Control in 
Health (INCQS - Fundação Oswaldo Cruz Brazil). All lipids were purchased from Sigma ${ }^{\circledR}$.

\section{Peptide Synthesis}

The peptide was synthesized manually according to the Fmoc chemistry (Merrifield, 1963). In each synthetic cycle, the deprotection of the $\alpha$-amino group deprotection was performed with $20 \%$ piperidine in DMF for $20 \mathrm{~min}$. The coupling reactions were performed with a threefold excess of DIC component and HoBt in DMF/DCM (1:1, v:v). After approximately $2 \mathrm{~h}$ of coupling, the ninhydrin test was performed to confirm the occurrence of the reaction. Final cleavage of the peptide from the resins and the deprotection of the side-chain protector groups were done by treatment with a solution containing TFA (94.5\%), deionized water (2.5\%), EDT $(2.5 \%)$, and TIS $(0.5 \%)$ at $25^{\circ} \mathrm{C}$ for $3 \mathrm{~h}$. After the cleavage procedure, the crude peptides were precipitated with ethyl ether, separated from the soluble non-peptidic contents by centrifugation, extracted into $10 \%$ acetic acid in water and lyophilized.

The analog peptide 0WHistatin 5 (0WHst 5) was synthesized with the addition of the amino acid tryptophan (W) in amino terminal extremity, as can be seen in Table 1. Because it is a fluorescent amino acid, with excitation at the wavelength of $280 \mathrm{~nm}$ and emission of fluorescence at the wavelength of $360 \mathrm{~nm}$, its addition allowed its monitoring by fluorescence technique, with greater sensitivity as can be seen in the following sections.

The purification process of the crude peptides was performed in semi-preparative HPLC with a Zorbax Eclipse XDB C18 reverse phase column $(9.4 \mathrm{~mm} \times 250 \mathrm{~mm}$ and $5 \mu \mathrm{m})$. The qualitative analysis was performed analytically using a Shimadzu LC-10A/C-47A separation system coupled to a Shimadzu LC-10A/C-47A UV/Vis detector with a Waters Symmetry C18 column $(2.1 \mathrm{~mm} \times 150 \mathrm{~mm}$ and $5 \mu \mathrm{m})$. The chromatographic conditions in the semi-preparative mode were: solvents A $\left(0.045 \%\right.$ TFA. $\left.\mathrm{H}_{2} \mathrm{O}\right)$ and $\mathrm{B}(0.036 \%$ TFA. $\mathrm{ACN})$, gradient of $0.33 \% / \mathrm{min}$ solvent $\mathrm{B}$ over $90 \mathrm{~min}$, flow rate of $5 \mathrm{ml} / \mathrm{min}$, and detection wavelength at $220 \mathrm{~nm}$. For the analytical mode, the conditions were: solvents A $(0.045 \%$ TFA. $\left.\mathrm{H}_{2} \mathrm{O}\right)$ and $\mathrm{B}(0.036 \%$ TFA.ACN $)$, gradient from 5 to $95 \%$ solvent $B$ in $30 \mathrm{~min}$, flow rate of $0.6 \mathrm{ml} / \mathrm{min}$, and detection wavelength at $220 \mathrm{~nm}$. After the purification procedure of the peptide, the molecule characterization was done using mass spectrometry. The analysis of pure peptides was performed by HPLC coupled to mass spectrometer operated in electrospray positive mode (LC/ESI-MS+) in a

TABLE 1 | Amino acid sequence of Histatin 5 and the synthesized OWHistatin 5 analog peptide.

\begin{tabular}{ll}
\hline Peptide & Amino acid sequence \\
\hline Histatin 5 & \\
& DSHAKRHHGYKRKFHEKH \\
OWHistatin 5 & HSHGY \\
& WDSHAKRHHGYKRKFHEK \\
& H H SHRY
\end{tabular}

Bruker $^{\circledR}$ type Ion Trap Amazon SL mass spectrometer. This procedure allowed to determine the quality and identity of the sample simultaneously.

\section{Preparation of Liposomes}

Three different liposome formulations were produced by the thin film hydration technique. The lipid film was composed of soy dipalmitoyl phosphatidylcholine (DPPC), cholesterol (Chol), polyethylene glycol (PEG), and 1-palmitoyl-2-oleoylsn-glycero-3-phospho-rac-1-glycerol (POPG). The lipid mixtures were dissolved in chloroform and then were evaporated under nitrogen flow, to form a thin lipid film in tube wall. For resuspension of the lipid film, solutions with or without the peptides solubilized in a $10 \mathrm{mM}$ Tris $\mathrm{HCl}$ buffer, $\mathrm{pH} 7.4$, was used. A suspension of large multilamellar vesicles (MLV's) was obtained and submitted to two different techniques for homogenization: extrusion, using Avanti Polar Lipids ${ }^{\circledR}$ extruder equipped with Nuclepore $^{\circledR}$ polycarbonate membrane, GE Healthcare Life Science, with pores of $100 \mathrm{~nm}$, and sonication, using titanium tip sonicator (QSonica ${ }^{\circledR}$ Q700).

\section{Physical Characterization of Liposomes Determination of the Mean Hydrodynamic} Diameter, Polydispersity Index, and Zeta Potential The mean hydrodynamic diameter (Z-Ave or d.nm) and polydispersity index (PDI) were determined by dynamic light scattering (DLS, Zetasizer Nano NS, Malvern Instruments ${ }^{\circledR}$, Malvern, UK). The zeta potential (ZP) of the liposomes was evaluated by the electrophoretic mobility of the particles according to the Helmholtz-Smoluchowski equation and processed using the Zetasizer Nano NS equipment software (Malvern Instruments). The suspensions of empty and loaded liposomes were diluted in $10 \mathrm{mM}$ Tris $\mathrm{HCl}$ buffer, $\mathrm{pH} 7.4$, in a 1:10 ratio. All experiments were run in triplicate at $25^{\circ} \mathrm{C}$.

\section{Encapsulation Efficiency}

The unencapsulated peptide separation was performed by molecular exclusion chromatography technique, using a Sephadex ${ }^{\circledR}$ G-50 column, with 10 mM Tris HCl buffer, 150 mM $\mathrm{NaCl}, \mathrm{pH}$ 7.4.

The fractions with liposomes were frozen in liquid nitrogen and lyophilized for $48 \mathrm{~h}$. Then $3 \mathrm{ml}$ of methanol were added to the samples, an aliquot of this solution was diluted in methanol and analyzed in spectrofluorometer to quantify the encapsulated peptide. Once the encapsulated peptide concentration was determined, the encapsulation efficiency, EE, was calculated using Equation 1.

$$
\mathrm{EE}(\%)=\frac{\text { Encapsulated peptide }}{\text { Total added peptide }} \times 100
$$

\section{Formulation Stability}

The produced formulations, F1, F2, and F3, were stored at $8^{\circ} \mathrm{C}$ and at $37^{\circ} \mathrm{C}$. The mean size, polydispersity index, and zeta potential were analyzed after $1,5,10,15,30,45$, and 60 days of storage. 


\section{In vitro Release Study}

The release kinetics of the encapsulated peptide was performed using the fluorescence technique, since the inserted tryptophan (W) provides fluorescence to the molecule. Spectrofluorometer Varian ${ }^{\circledR}$ CaryEclipse coupled to a circulation system of the solution $10 \mathrm{mM}$ Tris $\mathrm{HCl}, \mathrm{pH} 7.4$, was used. About $1 \mathrm{ml}$ of the solution of liposome and 0WHst 5 was added to a cellulose acetate dialysis membrane (Sigma-Aldrich ${ }^{\circledR}$ cut-off $14,000 \mathrm{kDa})$.

The peptide that permeated the dialysis tube and exited into the buffer solution was monitored by the Kinetics Varian ${ }^{\circledR}$ CaryEclipse software, with maximum fluorescence emission at $360 \mathrm{~nm}$ for $96 \mathrm{~h}$. The maximum fluorescence was plotted against the time and, by the use of the standard curve, the total peptide released by the system was evaluated by the plot of the maximum released concentration against the time.

\section{Time-Kill Curve Studies}

For the preparation of the standardized suspensions of C. albicans (ATCC 90028), an inoculum size of $1.10^{5} \mathrm{CFU} \mathrm{m}{ }^{-1}$ was used. Nine milliliters of Sabouraud Dextrose Broth (SDB) prepared with the microorganism were added in an Erlenmeyer for the growth control, $512 \mu \mathrm{g} \mathrm{ml}^{-1}$ of fluconazole was used for the positive control (cell death) and for testing the systems produced $1 \mathrm{ml}$ of the liposomal system encapsulated or not with $0 \mathrm{WHst}$ 5 was added. The Erlenmeyers were then incubated at $37^{\circ} \mathrm{C}$, under constant stirring, and aliquots of $100 \mu \mathrm{l}$ were withdrawn and serially diluted every $3 \mathrm{~h}$ for $12 \mathrm{~h}$. After this period, the aliquots were withdrawn and serial diluted every $12 \mathrm{~h}$ for $60 \mathrm{~h}$. About $100 \mu \mathrm{l}$ of each dilution were transferred to a plate with SDA and incubated for $48 \mathrm{~h}$. The colonies in each plate were then counted.

\section{Statistical Analysis}

$t$-Student test was used to verify the statistical difference between the last points of the time kill test curves. The level of significance was $90 \%$. The growth control and fluconazole curves were performed in duplicate.

\section{RESULTS AND DISCUSSION}

\section{Preparation of Liposomes}

In this work, three liposomal formulations were used according to the amounts shown in Table 2. The amounts are represented in mass. The peptide used was successfully obtained with high purity $(>95 \%)$ and loaded into the liposomes as described in the methodology section.

TABLE 2 | Lipid composition of the liposomes.

\begin{tabular}{lcccc}
\hline Formulation & DPPC & Chol & PEG & POPG \\
\hline F1 & 40 & 2 & - & - \\
F2 & 40 & 2 & 1 & - \\
F3 & 40 & 2 & - & 1
\end{tabular}

To determine the amount of extrusion cycles and sonication time required for the formation of the liposomes, periodic measurements were made in a spectrophotometer (Chorilli et al., 2013). The results shown in Figure 1 indicates that there is a decrease in absorbance at $410 \mathrm{~nm}$ as a function of sonication time and amount of extrusion cycles, respectively, for all formulations developed.

All the formulations produced required 15 extrusion cycles to be formed, thus, the addition of PEG in F2 and POPG in F3 did not promote differences in the number of extrusion cycles observed for $\mathrm{F} 1$ which does not have any of these components. When PEG and POPG were added to the formulation of these liposomes, the main objective was to promote better features like fluidity and stability to vesicles. For the sonication technique, monitoring was performed after every $2 \mathrm{~min}$, as seen in Figure 1B, and the stabilization of the absorbance values was achieved in the time of $4 \mathrm{~min}$ for all formulations. As in the extrusion, the addition of PEG and POPG in F2 and F3 did not affect the minimum time of 2 min of sonication observed for formulation F1 that does not contain these components.

\section{Physical Characterization of Liposomal Formulation}

The mean size, zeta potential, and polydispersity index (PDI) for empty and loaded liposomes with 0 WHst 5 , can be seen in Tables 3 and 4.

The mean size of the empty and sonicated liposomes was lower than for the empty liposomes obtained by extrusion. This can be observed by comparing the sizes for the empty liposomes obtained by extrusion and sonication seen in Tables 3 and 4 .

This fact is related to the technique of obtaining the liposomes. The $100 \mathrm{~nm}$ pores of the polycarbonate membrane used in the extruder, ensures final sizes closer to $100 \mathrm{~nm}$. In sonication, there is no way to control or predict the final mean size of the liposomes, which may vary as the amplitude, sonication time, and potency of the equipment change.

There was an increase in the mean size of loaded liposomes when compared to empty liposomes and this was observed for all formulations obtained by both techniques. According to Table 3, the empty F2 size was $97.2 \mathrm{~nm}$, and after the addition of 0 WHst 5 , it had a size of $119.2 \mathrm{~nm}$. For sonicated $\mathrm{F} 3$, the mean size before loading of the peptide was $82.2 \mathrm{~nm}$, rising to $133.6 \mathrm{~nm}$ with 0 WHst 5 . The same can be observed sonicated F1, which after addition of 0WHst 5 presented a $144.3 \mathrm{~nm}$, against $88.1 \mathrm{~nm}$ when empty. We observed an increase in size for liposomes after peptides had been encapsulated, and this indicates that 0 WHst 5 was incorporated into the liposomes, probably in the inner aqueous compartment because it is a water-soluble molecule (Nii and Ishii, 2005; Mohan et al., 2016). These data are interesting from the point of view of the intended application, which aims to stabilize the peptide and promote a better availability of it at the site of action.

The zeta potential of the produced liposomes is negative for all formulations prepared. The zeta potential value became less negative for all sonicated formulations after incorporation of the peptide. 0WHst 5 is a positively charged peptide 



FIGURE 1 | Effect of the amount of extrusion cycles on different liposome compositions (A) and effect of sonication time on different liposome compositions (B).

TABLE 3 | Size, PDI, and zeta potential for empty and loaded F1, F2, and F3 liposomes, obtained by extrusion.

\begin{tabular}{lccc}
\hline Formulation & Size $(\mathbf{n m})$ & PDI & $\begin{array}{c}\text { Zeta potential } \\
(\mathbf{m V})\end{array}$ \\
\hline F1 & $106.1 \pm 1.70$ & $0.128 \pm 0.06$ & $-49.8 \pm 1.17$ \\
F1/OWHst 5 & $116.6 \pm 0.30$ & $0.081 \pm 0.10$ & $-43.0 \pm 0.50$ \\
F2 & $97.1 \pm 1.77$ & $0.099 \pm 0.04$ & $-38.5 \pm 2.29$ \\
F2/OWHst 5 & $119.2 \pm 0.80$ & $0.087 \pm 0.08$ & $-42.2 \pm 0.90$ \\
F3 & $105.1 \pm 0.70$ & $0.113 \pm 0.06$ & $-42.7 \pm 1.89$ \\
F3/OWHst 5 & $112.6 \pm 0.50$ & $0.068 \pm 0.08$ & $-47.4 \pm 0.50$ \\
\hline
\end{tabular}

TABLE 4 | Size, PDI, and zeta potential for empty and loaded F1, F2, and F3 liposomes, obtained by sonication.

\begin{tabular}{lccc}
\hline Formulation & Size $(\mathbf{n m})$ & PDI & $\begin{array}{c}\text { Zeta potential } \\
\mathbf{( m V})\end{array}$ \\
\hline F1 & $88.1 \pm 8.03$ & $0.371 \pm 0.01$ & $-51.4 \pm 8.94$ \\
F1/OWHst 5 & $144.3 \pm 0.35$ & $0.255 \pm 0.01$ & $-48.6 \pm 0.21$ \\
F2 & $96.4 \pm 10.41$ & $0.382 \pm 0.05$ & $-56.4 \pm 2.28$ \\
F2/OWHst 5 & $147.4 \pm 1.45$ & $0.124 \pm 0.09$ & $-51.5 \pm 1.79$ \\
F3 & $82.2 \pm 4.77$ & $0.287 \pm 0.02$ & $-56.5 \pm 3.78$ \\
F3/OWHst 5 & $133.6 \pm 0.82$ & $0.241 \pm 0.01$ & $-52.3 \pm 8.17$ \\
\hline
\end{tabular}

TABLE 5 | Efficiency of encapsulation for the formulations F1, F2, and F3.

\begin{tabular}{lcc}
\hline Formulation & Extrusion (\%) & Sonication (\%) \\
\hline F1 & 17.7 & 34.5 \\
F2 & 9.5 & 12.2 \\
F3 & 12.7 & 14.2 \\
\hline
\end{tabular}

(net charge at $\mathrm{pH} 7:+5.7)$ that interferes with the final charge of the liposomes, making them less negative. The POPG lipid used in the F3 formulation is anionic and confers a greater amount of negative charges to the external lipid bilayer which may be less influenced by the positive charge of 0WHst 5. The standard zeta potential value used for this is $\pm 30 \mathrm{mV}$ (Ebrahimi et al., 2015; Berbel Manaia et al., 2017; Sato et al., 2017). The sonicated and extruded encapsulated F1, F2, and F3 formulations have zeta potential in the range of -30 to $-50 \mathrm{mV}$, indicating that all formulations are stable.
PDI values in the range of 0.07 to 0.09 were found for all extruded formulations containing 0 WHst 5 , as can be seen in Table 3. Thus, it can be stated that there is a monodispersion. For sonication, PDI values of $0.371,0.382$, and 0.287 were found for empty F1, F2, and F3, respectively, indicating homogeneity of the analyzed sample. However, there are vesicles in other size ranges, characterizing a polydispersity.

The PDI values fell to $0.255,0.124$, and 0.241 , respectively, when 0 WHst 5 was loaded into the liposomes prepared by sonication. Addition of the peptide to the formulations made them more homogeneous. The same effect was also observed for the liposomes obtained by extrusion, with 0.128 of PDI for empty and 0.081 for loaded F1 formulation.

\section{Encapsulation Efficiency}

The encapsulation efficiency (EE) for the 0WHst 5 is below $40 \%$, as seen in Table 5. Addition of cholesterol to all formulations may have hindered encapsulation. This component prevents the phase transition of the lipid bilayers and always maintains them in a state of intermediate fluidity, tending to be more rigid, which hinders the incorporation of molecules (Roy et al., 2016).

However, EE was higher for formulations produced by sonication, with the highest value of $34.5 \%$ for F1. This formulation also showed the highest efficiency among the formulations obtained by extrusion, with a value of $17.7 \%$. F1 is composed of DPPC and cholesterol, DPPC has $T_{\mathrm{m}}$ (phase transition temperature) of $42^{\circ} \mathrm{C}$, with a room temperature of $25^{\circ} \mathrm{C}$ bilayer is in its gel phase and rigid. Even so, it is the formulation that incorporated the largest amount of the peptide for the two techniques used.

The absence of other components contributed to the incorporation of the peptide according to this methodology. The presence of PEG in F2 and POPG in F3 made it difficult to incorporate $0 \mathrm{WH}$ st 5 into the liposomes. The encapsulation efficiency for F3 was little higher when compared to F2. The presence of POPG in this formulation aims to favor the crystalline liquid phase of the bilayer and grant more fluidity, since this lipid has $T_{\mathrm{m}}$ of $-2^{\circ} \mathrm{C}$, contributing the incorporation of the peptide. The lower EE was for F2, which has PEG in its composition. However, the presence of this component increases the physical-chemical stability of the liposomes, as will be seen in the following results. The increase in stability 
prolongs their presence in the human organism, by decreasing the uptake of the vesicles by the cells of the immune system and favors adherence in mucous membranes (Ron-Doitch et al., 2016; Jøraholmen et al., 2017), which may be a desirable characteristic for the intended application.

\section{Stability Studies}

According to Figure 2A, there were slight changes in average size and PDI for the sonicated F1 stored at $4^{\circ} \mathrm{C}$. For this reason, sonication produced liposomes with better stability than the extrusion, maintaining the formulation stable during 60 days at $4^{\circ} \mathrm{C}$. Storage at $37^{\circ} \mathrm{C}$ was more damaging to all formulations, providing many variations on mean size and PDI over time, which was also observed by Çelik et al. (2017).

The temperature of $4^{\circ} \mathrm{C}$ favors the storage of liposomes obtained by both techniques. It can be observed that for F2 (Figures 2A,B) up to 30 days, the average size and PDI did not show great variations, and after 45 days, a small variation of average size, from approximately 160 to $130 \mathrm{~nm}$ for sonication and from 160 to $110 \mathrm{~nm}$ for extrusion, with increase of PDI. Sonicated F1 and F2 presented better parameters and better stability when stored at $4^{\circ} \mathrm{C}$. F2 has PEG in its composition, which according to some studies favors the maintenance of vesicle stability as also observed by Rai et al. (2008). Even though it does not favor encapsulation efficiency, as discussed previously, this component helps to maintain the stability of the formulation, which remains intact for longer when stored at $4^{\circ} \mathrm{C}$.

Sonicated F3 is the most stable formulation compared to F1 and F2, according to the graphs of Figures $2 \mathrm{~A}$ and $\mathbf{3 A}$.

In general, the best storage temperature is $4^{\circ} \mathrm{C}$ for all formulations. The technique that presents better stability is sonication. The lipids used in the liposomes may influence the stability, since the best stability was for F3, which has POPG in its composition. This component provides a more fluidity to the lipid bilayer, which can generate better adaptation throughout the storage period. POPG also confers a greater

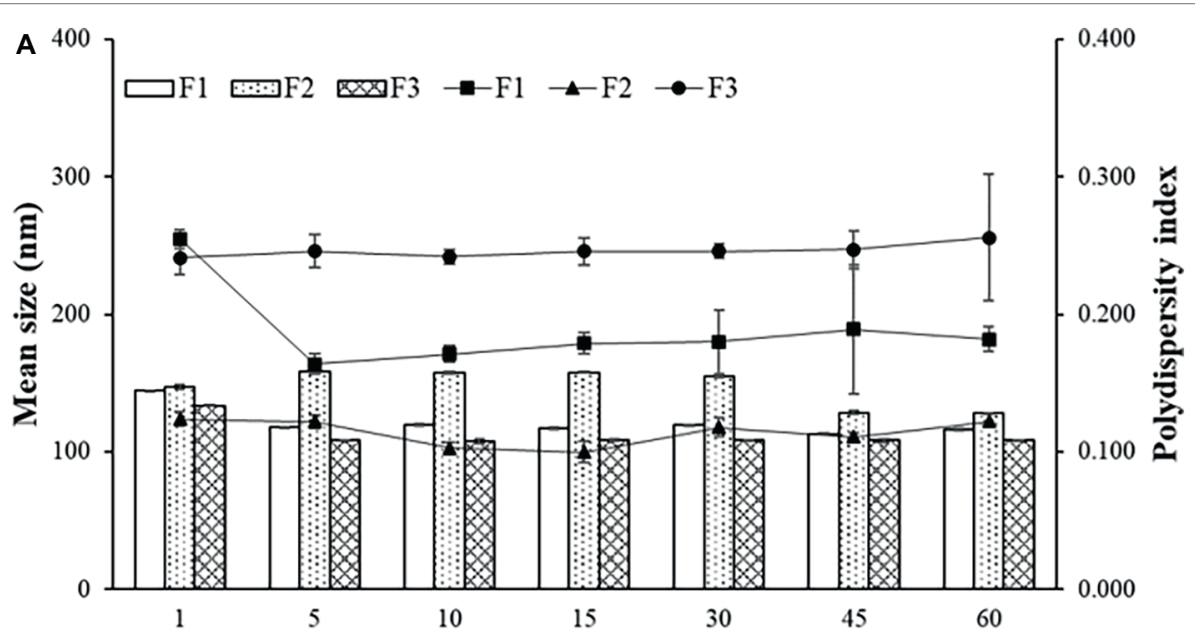

Time (days)

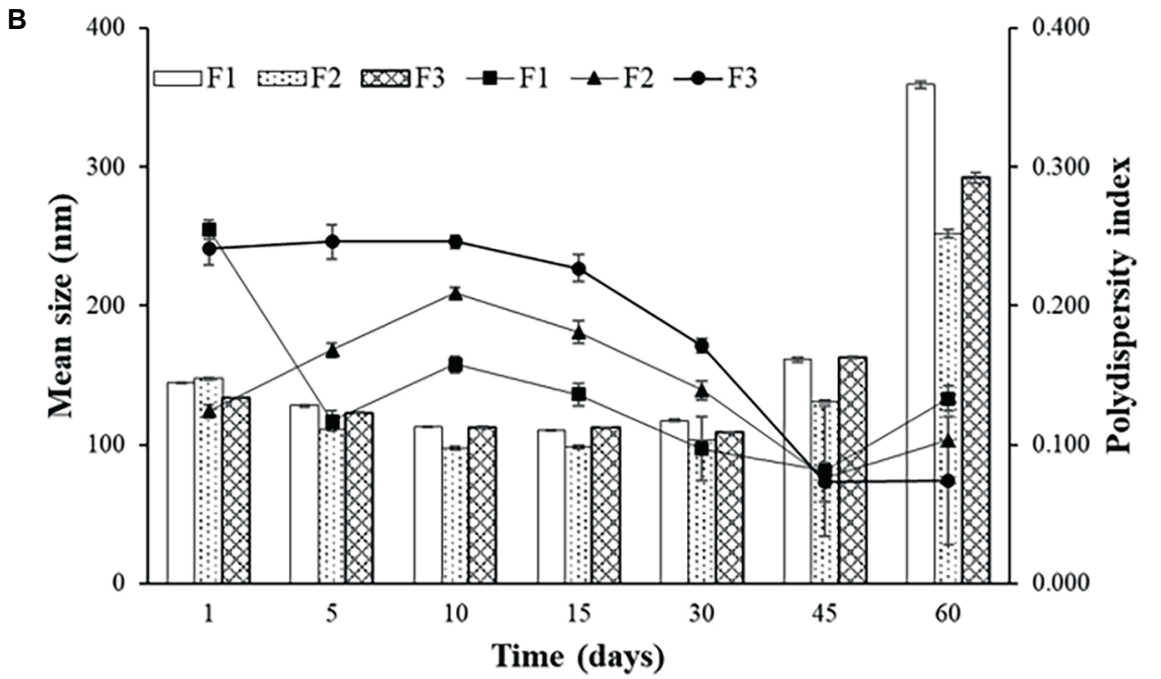

FIGURE 2 | Mean size and polydispersity index (PDI) for F1, F2, and F3 obtained by sonication stored at $4^{\circ} \mathrm{C}(\mathbf{A})$ and at $37^{\circ} \mathrm{C}(\mathbf{B})$. 



FIGURE 3 | Mean size and polydispersity index (PDI) for F1, F2, and F3 obtained by extrusion stored at $4^{\circ} \mathrm{C}$ (A) and at $37^{\circ} \mathrm{C}$ (B).

amount of negative charges to the bilayer, which difficult the aggregation of the liposomes. F2, which contains PEG, also showed better stability than F1, which has only DPPC and cholesterol. The addition of different lipids to the liposomes has made peptide encapsulation more difficult as previously seen, but may improve stability, as seen in these results.

\section{In vitro Release Study}

Graph A of Figure 4 represents the crossing of the unencapsulated peptide over the dialysis membrane. This test was performed as a control for the release experiments of the developed liposomal system. Thus, it was possible to know the time required for the non-encapsulated peptide to leave the dialysis membrane, once the peptide encapsulated in the liposomes would only come out after its rupture, which would take a longer time. The total crossing over of the unencapsulated peptide occurs after 5 h. For F1, F2, and F3 (Figures 4B-D), a 5-h time release peak is observed, similar to the unencapsulated peptide release profile.
The release profile indicates the occurrence of burst effect, which is characterized by the large amount of drug that is released in the first $24 \mathrm{~h}$ (Huang and Brazel, 2001). This effect is advantageous since the release of a large amount of $0 \mathrm{WHst}$ 5 in a short period of time can be used as the dose of attack to inhibit the growth of microorganisms moments after its application at the site of action. Because it is a release system that is intended for topical application for the treatment of oral lesions caused by $C$. albicans, a rapid release directly at the site of action would rapidly inhibit the proliferation of the microorganism (Huang and Brazel, 2001).

For all formulations, the profiles observed for extrusion and sonication were similar, and the use of distinct techniques for the production of liposomes does not interfere with their release kinetics. The burst effect observed in the first $5 \mathrm{~h}$ indicates that the released content is not encapsulated in the liposomes, or that it may be interacting with its outer surface, as also observed by Calienni et al. (2017). Thus, the release process for these liposomes occurs in two steps, initially there is a rapid release, 

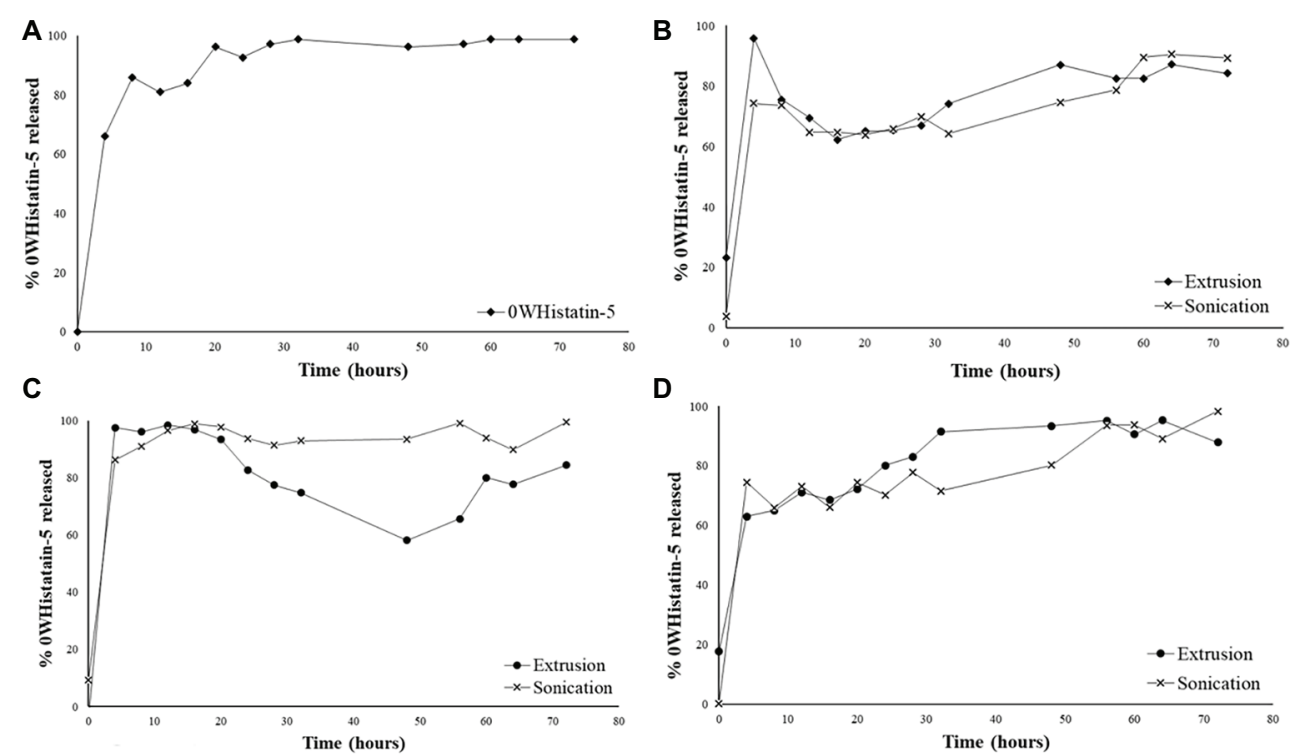

FIGURE 4 | Release profile for: free OWHistatin 5 (A); F1 (B); F2 (C); and F3 (D), loaded with OWHistatin 5.

followed by a drop indicating the dialysis system's equilibrium due to osmotic forces. In a second moment, release of the remaining amount of the peptide occurs slowly for $80 \mathrm{~h}$. The slow release step is related to disruption of the liposomes, which thereby releases the peptide contained therein (Lopes et al., 2012).

The release kinetics for nanocarriers is related to their encapsulation efficiency (EE) and stability. A higher EE will certainly result in a higher release peak, especially if burst effect occurs (Luan et al., 2006). Thus, in general, the formulations obtained by sonication, which have higher EE, also show greater increase in their second moment in the release profile.

\section{Killing Curve Studies}

The experimental points shown in the graphs were calculated according to Equation 2, where $F$ is the dilution factor, $C$ is the colony forming unit count, and $V$ is the volume of the portion used in the final dilution. The uncertainty of each experimental point was calculated from the standard uncertainty values and expanded uncertainty according to Corry et al. (2007) and Niemi and Niemelä (2001). The error bars do not appear in the graphs presented, since the expanded uncertainties presented results of one to two orders of magnitude lower than the experimental values.

$$
y(U F C / m l)=F \cdot \frac{C}{V}
$$

ATCC 90028 was used in this test because it is considered a standard strain for screening tests for new antifungal agents. Besides, this study is based on the proposal of developing a liposomal system capable of prolonging the release of the antifungal peptide Histatin 5. The idea emerged from two studies of our research group involving this peptide for the treatment and prevention of oral candidiasis, mainly caused by C. albicans (Moffa et al., 2015a,b).
Previously, MIC assay was performed, and the values found for this strain were $128 \mu \mathrm{g} \mathrm{ml}^{-1}$ for fluconazole and $257.8 \mu \mathrm{g} \mathrm{ml}^{-1}$ for Histatin 5, as well as for the analog peptide 0WHistatin 5 . The concentration of $512 \mu \mathrm{g} \mathrm{ml}^{-1}$ for fluconazole in the time kill assay represents four times the MIC value, since the intention was to visualize the cell death caused by the drug, which was used as a positive control. For the peptide, the MIC value was used since it was also the value used to prepare the liposomes and perform the encapsulation efficiency tests.

MIC assay was performed following the M27-A3 methodology of the Clinical and Laboratory Standards Institute Manual with the peptides 0WHistatin 5 and Histatin 5 using SB medium. This medium was chosen to provide enough nutrients to the microorganism during the $72 \mathrm{~h}$ of the time kill assay. It was necessary that there was enough amount of nutrients in the medium to promote the microorganism growth for the total time, because the developed system showed release for more than $60 \mathrm{~h}$. Therefore, the observed death effect would be caused by the action of the peptide 0WHistatin 5 and not due to lack of nutrients.

The obtained result is consistent with the literature, and the MIC value for Histatin 5 and 0 WHistatin 5 was $64.45 \mu \mathrm{g} \mathrm{ml}^{-1}$. Thus, the use of the SB medium did not interfere with the antifungal activity of the peptide and indicated that it can be used to perform time kill assays.

To determine MIC for the liposomal preparations is not possible, because the encapsulated peptide is in the liposome internal aqueous compartment, and, when serial dilutions are made, only the number of liposomes present in solution is diluted, while their internal concentration is not.

The internal concentration was determined by calculating the encapsulation efficiency. Therefore, performing a serial dilution test, such as the MIC, would not give us an enlightening result regarding the concentration of liposomal system to 


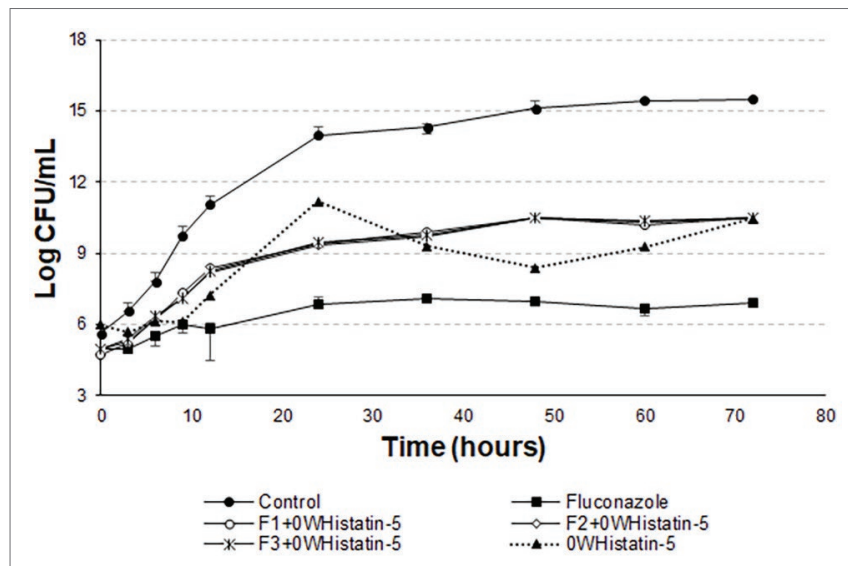

FIGURE 5 | Time-kill curves for C. albicans (ATCC 90028) treated with extruded F1, F2, and F3 loaded with OWHistatin 5 . The lines referring to $\mathrm{F} 1+$ OWHistatin 5, F2 + OWHistatin 5, and F3 + OWHistatin 5 systems are overlapping because the number of counted colonies were close.

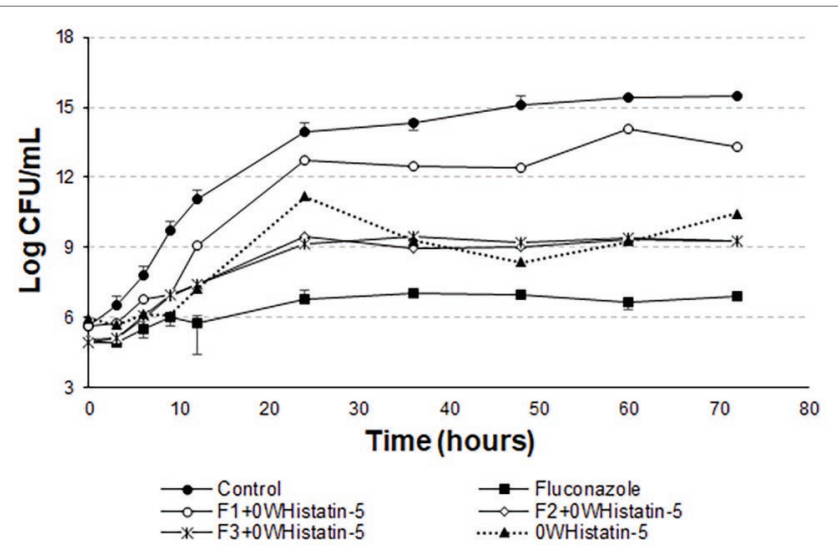

FIGURE 6 | Time-kill curves for C. albicans (ATCC 90028) treated with sonicated F1, F2, and F3 loaded with OWHistatin 5. The lines referring to F2 + OWHistatin 5and F3 + OWHistatin 5 systems are overlapping because the number of counted colonies was close.

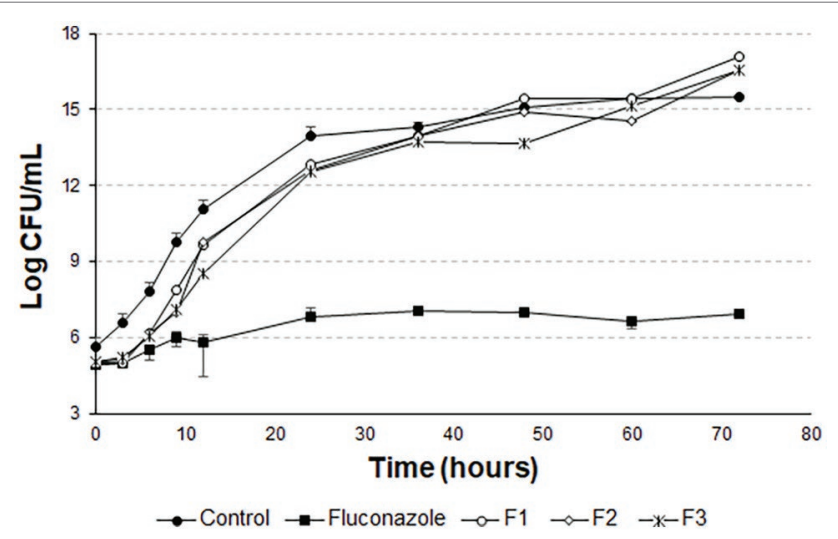

FIGURE 7 | Time-kill curves for C. albicans (ATCC 90028) treated with sonicated and empty F1, F2, and F3. be used. Thus, it was determined $1 \mathrm{ml}$ of liposomal system for use in the tests to make it possible to apply the value obtained in the encapsulation efficiency tests to estimate the concentration of the encapsulated peptide.

Data of the time-kill assay (Figure 5) show that for $12 \mathrm{~h}$ the peptide inhibited the growth of the microorganism the same way that fluconazole. A dose of $257.8 \mu \mathrm{g} \mathrm{ml}^{-1}$ of $0 \mathrm{WHst}$ 5 and a dose of $512 \mu \mathrm{g} \mathrm{ml} l^{-1}$ of fluconazole were used, demonstrating that 0 WHst 5 in a lower dosage is capable of performing the same inhibition. This result is in agreement with Moffa et al. (2015b), which found inhibition in the range of $800-25 \mu \mathrm{g} \mathrm{ml}^{-1}$ for Hst 5. When incubating the peptide with C. albicans for only $1.5 \mathrm{~h}$, Moffa et al. (2015b) obtained an approximate $2-\log$ reduction in the $\mathrm{CFU} \mathrm{ml} \mathrm{m}^{-1}$. As shown in the graph of Figure 5, after $12 \mathrm{~h}$ at 4 -log reduction in CFU ml ${ }^{-1}$ was observed.

The $t$-student test showed that the means of the last point of the growth control curve and the last point of the curves $\mathrm{F} 1+0$ WHistatin 5, F2 + 0WHistatin 5, F3 + 0WHistatin 5, and 0 WHistatin 5 were statistically different, at the level of significance of $90 \%$. This occurred for the systems produced by extrusion and sonication and showed that the produced liposomal system was effective in controlling the growth of C. albicans. This demonstrates that with prolonged treatment with 0 WHst 5 , it is possible to further reduce the growth of the microorganism.

However, Moffa et al. (2015a) proves that Hst 5 undergoes proteolytic action when present in human saliva, in addition to complexing with the enzyme salivary amylase, which leads to a decrease in the antifungal action of the peptide. These two effects occur rapidly as soon as the peptide is mixed with the total human saliva content. Encapsulating this peptide in liposomes is an attempt to protect it from these actions, allowing it to act for an extended period when added to its site of action. The data for the liposomal systems developed in this work (Figures 5 and 6) demonstrated prolonged activity for all the produced formulations, as well as the peptide 0 WHistatin 5 . This proves that the encapsulated peptide does not lose its action and maintains its antifungal potential. In addition, encapsulating the peptide in the

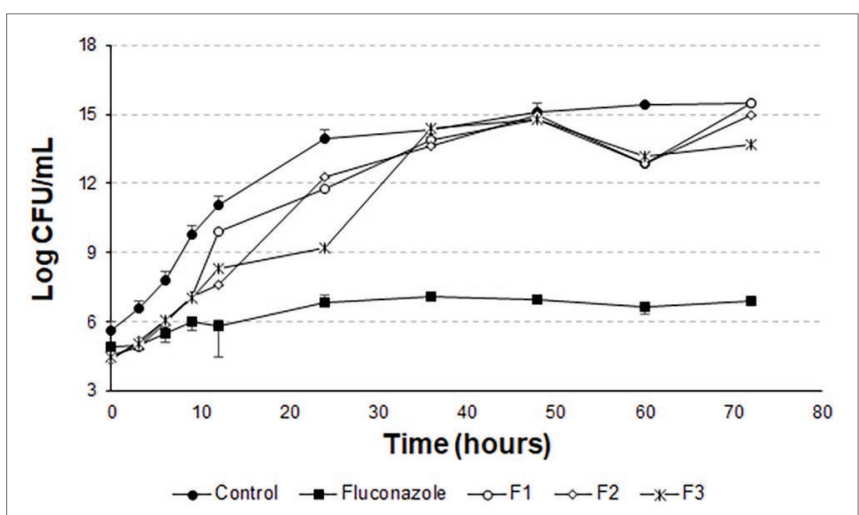

FIGURE 8 | Time-kill curves for C. albicans (ATCC 90028) treated with extruded and empty F1, F2, and F3. 
liposomes improves the growth limitation, as it becomes more stable than for the non-encapsulated peptide. In Figure 5, after $24 \mathrm{~h}$ of incubation, there was a 3 -log reduction in $\mathrm{CFU} \mathrm{ml} \mathrm{m}^{-1}$, which remained constant during the $72-\mathrm{h}$ test, reaching a reduction of $4 \operatorname{logs}$ in $\mathrm{CFU} \mathrm{ml} \mathrm{m}^{-1}$ at the end. For liposomes obtained by sonication (Figure 6), after $24 \mathrm{~h}$ incubation, the reduction was $4 \operatorname{logs}$ for F2 and F3 and 2 logs for F1. This reduction was also maintained over the 72 -h test period. For F2 and F3, the reduction was 6 logs at $72 \mathrm{~h}$.

Han et al. (2016) inhibited close to $100 \%$ of C. albicans cells by treating them with $16 \mu \mathrm{g} \mathrm{ml}^{-1} \mathrm{Hst} 5$, after a total time of $1 \mathrm{~h}$. This demonstrates that this peptide acts very well in the first few moments after addition to the medium. Thus, this study demonstrates that the use of a nanocarrier, such as liposomes, is able to prolong the time of peptide action, inhibiting the growth of the microorganism for $72 \mathrm{~h}$.

The $t$-student test was applied to compare the last points of the F1, F2, and F3 curves with the last point of the growth control curve. For F1, the means compared are statistically equal. For F2 and F3, the means are statistically different. However, it can be noted from Figure 8 that there is no pronounced cell death as in Figures $\mathbf{5}$ and $\mathbf{6}$.

In Figure 7, the means of the last points of F1, F2, F3, and growth control are statistically different. There is also no pronounced cell death, as in Figure 8. This demonstrates that the liposomal system without the peptide 0WHst 5 does not affect the growth of $C$. albicans, with 0 WHst 5 being responsible for the effect discussed above.

\section{CONCLUSION}

The results obtained in this work indicate that the extruded liposomes are more homogeneous while the sonicated liposomes have a greater polydispersity. However, encapsulation efficiency values were higher for sonicated liposomes, which also produced more stable liposomes during storage at $4^{\circ} \mathrm{C}$, among which F3 was the most stable. The results observed in the release

\section{REFERENCES}

Baev, D., Li, X. S., Dong, J., Keng, P., and Edgerton, M. (2002). Human salivary Histatin 5 causes disordered volume regulation and cell cycle arrest in Candida albicans. Infect. Immun. 70, 4777-4784. doi: 10.1128/IAI.70.9. 4777-4784.2002

Berbel Manaia, E., Paiva Abuçafy, M., Chiari-Andréo, B. G., Lallo Silva, B., Oshiro-Júnior, J. A., and Chiavacci, L. (2017). Physicochemical characterization of drug nanocarriers. Int. J. Nanomedicine 12, 4991-5011. doi: $10.2147 /$ IJN.S133832

Berkow, E., and Lockhart, S. (2017). Fluconazole resistance in Candida species: a current perspective. Infect. Drug Resist. 10, 237-245. doi: 10.2147/IDR.S118892

Calienni, M. N., Temprana, C. F., Prieto, M. J., Paolino, D., Fresta, M., Tekinay, A. B., et al. (2017). Nano-formulation for topical treatment of precancerous lesions: skin penetration, in vitro, and in vivo toxicological evaluation. Drug Deliv. Transl. Res. 8, 1-19. doi: 10.1007/s13346-017-0469-1

Cannon, R. D., Lamping, E., Holmes, A. R., Niimi, K., Tanabe, K., Niimi, M., et al. (2007). Candida albicans drug resistance another way to cope with stress. Microbiology 153, 3211-3217. doi: 10.1099/mic.0.2007/010405-0 kinetics studies indicate that there is a relationship between the stability of the liposome formulation and the release profile over time, the liposomes exhibit good stability, which controlled and prolonged release of the peptide. The time-kill results using ATCC 90028 showed that the liposomal systems preserved the antifungal activity of the peptide and were able to limit yeast growth for $72 \mathrm{~h}$. As the results were promising and demonstrated to limit the growth of this microorganism, the intent of the research group is testing the systems for other strains, including clinical isolates and resistant strains of C. albicans. We can conclude that the liposomal system produced has the potential to limit the growth of the microorganism. Complementary tests, such as system degradation in human saliva and in vivo tests are the future steps off this work.

\section{AUTHOR CONTRIBUTIONS}

CZ performed all the experiments and wrote the manuscript. FF assisted in the time kill test and collaborated with the manuscript correction. EJ carried out the purification and characterization by mass spectroscopy of the peptide and critically reviewed the manuscript. PS characterized liposomes and assisted in the discussion of these results. FP elaborated, analyzed the data, and contributed to the discussion of time kill tests. MC and SG supervised the project and did the final revision of the manuscript.

\section{FUNDING}

This work was supported by grants from FAPESP (proc. 2013/19370-2 and 2018/03018-1).

\section{ACKNOWLEDGMENTS}

$\mathrm{CZ}$ and FF thank CAPES and CNPq foundations for Ph.D. and Master fellowship, respectively.

Çelik, B., Sağıroğlu, A. A., and Özdemir, S. (2017). Design, optimization and characterization of coenzyme Q10- and D-panthenyl triacetate-loaded liposomes. Int. J. Nanomedicine 12, 4869-4878. doi: 10.2147/IJN.S140835

Chorilli, M., Calixto, G., Rimério, T. C., and Scarpa, M. V. (2013). Caffeine encapsulated in small unilamellar liposomes: characterization and in vitro release profile. J. Dispers. Sci. Technol. 34, 1465-1470. doi: 10.1080/01932691.2012.739535

Corry, J. E., Jarvis, B., Passmore, S., and Hedges, A. (2007). A critical review of measurement uncertainty in the enumeration of food micro-organisms. Food Microbiol. 24, 230-253. doi: 10.1016/j.fm.2006.05.003

De Araújo, D. R., Pinto, L. D. M. A., Braga, A. D. F. D. A., and de Paula, E. (2003). Formulações de anestésicos locais de liberação controlada: aplicações terapêuticas. Rev. Bras. Anestesiol. 53, 663-671. doi: 10.1590/S003470942003000500014

Ebrahimi, H. A., Javadzadeh, Y., Hamidi, M., and Jalali, M. B. (2015). Repaglinideloaded solid lipid nanoparticles: effect of using different surfactants/stabilizers on physicochemical properties of nanoparticles. DARU J. Pharm. Sci. 23:46. doi: 10.1186/s40199-015-0128-3

Frézard, F., Schettini, D. A., Rocha, O. G. F., and Demicheli, C. (2005). Lipossomas: propriedades físico-químicas e farmacológicas, aplicações na quimioterapia 
à base de antimônio. Quim Nova 28, 511-518. doi: 10.1590/ S0100-40422005000300025

Han, J., Jyoti, M. A., Song, H.-Y., and Jang, W. S. (2016). Antifungal activity and action mechanism of Histatin 5-halocidin hybrid peptides against Candida ssp. PLoS One 11:e0150196. doi: 10.1371/journal. pone.0150196

Hawser, S. P., and Douglas, L. J. (1995). Resistance of Candida albicans biofilms to antifungal agents in vitro. Antimicrob. Agents Chemother. 39, 2128-2131. doi: 10.1128/AAC.39.9.2128

Helmerhorst, E. J., Breeuwer, P., van 't Hof, W., Walgreen-Weterings, E., Oomen, L. C. J. M., Veerman, E. C. I., et al. (1999). The cellular target of Histatin 5 on Candida albicans is the energized mitochondrion. J. Biol. Chem. 274, 7286-7291. doi: 10.1074/jbc.274.11.7286

Huang, X., and Brazel, C. S. (2001). On the importance and mechanisms of burst release in matrix-controlled drug delivery systems. J. Control. Release 73, 121-136. doi: 10.1016/S0168-3659(01)00248-6

Johnson, E. M., Warnock, D. W., Luker, J., and Porter, S. R. (1995). Emergence of azole drug resistance in Candida species from HIV-infected patients receiving prolonged fluconazole therapy for oral candidosis. J. Antimicrob. Chemother. 35, 103-114. doi: 10.1093/jac/35.1.103

Jøraholmen, M. W., Basnet, P., Acharya, G., and Škalko-Basnet, N. (2017). PEGylated liposomes for topical vaginal therapy improve delivery of interferon alpha. Eur. J. Pharm. Biopharm. 113, 132-139. doi: 10.1016/j. ejpb.2016.12.029

Konopka, K., Dorocka-Bobkowska, B., Gebremedhin, S., and Düzgüneş, N. (2010). Susceptibility of Candida biofilms to H 5 and fluconazole. Antonie Van Leeuwenhoek 97, 413-417. doi: 10.1007/s10482-010-9417-5

Lopes, S., Simeonova, M., Gameiro, P., Rangel, M., and Ivanova, G. (2012). Interaction of 5-fluorouracil loaded nanoparticles with 1,2-dimyristoyl-snglycero-3-phosphocholine liposomes used as a cellular membrane model. J. Phys. Chem. B 116, 667-675. doi: 10.1021/jp210088n

Luan, X., Skupin, M., Siepmann, J., and Bodmeier, R. (2006). Key parameters affecting the initial release (burst) and encapsulation efficiency of peptidecontaining poly(lactide-co-glycolide) microparticles. Int. J. Pharm. 324, 168-175. doi: 10.1016/j.ijpharm.2006.06.004

Merrifield, R. B. (1963). Solid phase peptide synthesis. I. The synthesis of a tetrapeptide. J. Am. Chem. Soc. 85, 2149-2154. doi: 10.1021/ja00897a025

Moffa, E. B., Machado, M. A. A. M., Mussi, M. C. M., Xiao, Y., Garrido, S. S., Giampaolo, E. T., et al. (2015a). In vitro identification of Histatin 5 salivary complexes. PLoS One 10, 1-13. doi: 10.1371/journal. pone. 0142517

Moffa, E. B., Mussi, M. C. M., Xiao, Y., Garrido, S. S., Machado, M. A. A. M., Giampaolo, E. T., et al. (2015b). Histatin 5 inhibits adhesion of C. albicans to reconstructed human oral epithelium. Front. Microbiol. 6, 1-7. doi: 10.3389/ fmicb. 2015.00885

Mohan, A., McClements, D. J., and Udenigwe, C. C. (2016). Encapsulation of bioactive whey peptides in soy lecithin-derived nanoliposomes: influence of peptide molecular weight. Food Chem. 213, 143-148. doi: 10.1016/j. foodchem.2016.06.075
Niemi, R. M., and Niemelä, S. I. (2001). Measurement uncertainty in microbiological cultivation methods. Accred. Qual. Assur. 6, 372-375. doi: $10.1007 / \mathrm{s} 007690100360$

Nii, T., and Ishii, F. (2005). Encapsulation efficiency of water-soluble and insoluble drugs in liposomes prepared by the microencapsulation vesicle method. Int. J. Pharm. 298, 198-205. doi: 10.1016/j.ijpharm.2005.04.029

Rai, P., Vance, D., Poon, V., Mogridge, J., and Kane, R. S. (2008). Stable and potent polyvalent anthrax toxin inhibitors: raft-inspired domain formation in liposomes that contain PEGylated lipids. Chem. Eur. J. 14, 7748-7751. doi: 10.1002/chem.200801097

Robbins, N., Wright, G. D., and Cowen, L. E. (2016). "Antifungal drugs: the current armamentarium and development of new agents" in Microbiology Spectrum 4 (American Society of Microbiology), 903-922. doi: 10.1128/ microbiolspec.Funk-0002-2016

Ron-Doitch, S., Sawodny, B., Kühbacher, A., David, M. M. N., Samanta, A., Phopase, J., et al. (2016). Reduced cytotoxicity and enhanced bioactivity of cationic antimicrobial peptides liposomes in cell cultures and 3D epidermis model against HSV. J. Control. Release 229, 163-171. doi: 10.1016/j.jconrel.2016.03.025

Roy, B., Guha, P., Bhattarai, R., Nahak, P., Karmakar, G., Chettri, P., et al. (2016). Influence of lipid composition, $\mathrm{pH}$, and temperature on physicochemical properties of liposomes with curcumin as model drug. J. Oleo Sci. 65, 399-411. doi: 10.5650/jos.ess 15229

Salade, L., Wauthoz, N., Deleu, M., Vermeersch, M., De Vriese, C., Amighi, K., et al. (2017). Development of coated liposomes loaded with ghrelin for nose-to-brain delivery for the treatment of cachexia. Int. J. Nanomedicine 12, 8531-8543. doi: 10.2147/IJN.S147650

Sato, M. R., Oshiro Junior, J. A., Machado, R. T. A., de Souza, P. C., Campos, D. L., Pavan, F., et al. (2017). Nanostructured lipid carriers for incorporation of copper(II) complexes to be used against Mycobacterium tuberculosis. Drug Des. Devel. Ther. 11, 909-921. doi: 10.2147/DDDT.S127048

Seo, M.-D., Won, H.-S., Kim, J.-H., Mishig-Ochir, T., and Lee, B.-J. (2012). Antimicrobial peptides for therapeutic applications: a review. Molecules 17, 12276-12286. doi: 10.3390/molecules 171012276

Voltan, A., Quindós, G., Alarcón, K., Fusco-Almeida, A. M., Mendes-Giannini, M. J., and Chorilli, M. (2016). Fungal diseases: could nanostructured drug delivery systems be a novel paradigm for therapy? Int. J. Nanomedicine 11, 3715-3730. doi: 10.2147/IJN.S93105

Conflict of Interest Statement: The authors declare that the research was conducted in the absence of any commercial or financial relationships that could be construed as a potential conflict of interest.

Copyright (c) 2019 Zambom, da Fonseca, Crusca, da Silva, Pavan, Chorilli and Garrido. This is an open-access article distributed under the terms of the Creative Commons Attribution License (CC BY). The use, distribution or reproduction in other forums is permitted, provided the original author(s) and the copyright owner(s) are credited and that the original publication in this journal is cited, in accordance with accepted academic practice. No use, distribution or reproduction is permitted which does not comply with these terms. 